\title{
Comparison of Comfort Performance Criteria and Sensing Approach in Office Space: Analysis of the Impact on Shading Devices' Efficiency
}

\author{
Marco Imperadori, Tiziana Poli, Juan Diego Blanco Cadena, \\ Federica Brunone and Andrea G. Mainini
}

\begin{abstract}
Indoor occupant comfort has been related to total building energy consumption, and some of its components (lighting, heating, and cooling mainly), together with carbon production, also with occupants' productivity, learnability, and health. However, few works relate comfort to the circular economy and are barely related to the circularity of the selected building materials or systems. This work is intended to evaluate how the dynamism of a building envelope (triggered by different comfort preferences) disturbs the efficiency of the building and maintenance activities (Linked with the following correlated research projects: (1) Research title: Imaging processing on determining eye strain (ongoing), Participant research groups: VELUXlab \& SEEDLab.ABC).
\end{abstract}

Keywords Interactive buildings - Visual comfort - User-centered approach • Building operation maintenance

\section{Occupants' Comfort and Energy}

A significant share of the energy consumed by buildings is intended for delivering proper indoor conditions for most of its occupants. These proper indoor conditions are generally referred as comfort conditions, which have been defined by ASHRAE 55 as "...condition of mind which expresses satisfaction with the environment...." Therefore, it encompasses different components, namely thermal, visual, acoustic, air quality, layout distribution, and others.

The indoor environment depends on the combination of various physical parameters, and hence, multiple plant systems are needed for managing all of them in parallel. Most of the plant systems have a dynamic operation, with the intention of properly handle the physical parameter variations, generated by mutable weather

\footnotetext{
M. Imperadori · T. Poli (更) · J. D. Blanco Cadena · F. Brunone · A. G. Mainini Architecture, Built Environment and Construction Engineering-ABC Department, Politecnico di Milano, Milan, Italy e-mail: tiziana.poli@polimi.it
} 
conditions during the building lifetime. To do so, there must be a performance criterium, or criteria, to rate the efficiency of the processes carried out by the system and to trigger an intervention when the goals set are not met.

As the closest element to the exterior, the building envelope is the most influential building system for providing well-being indoors, and in particular the transparent portion (defined as the quickest path for heat, light, sound, and pollution transfer). Additional shading devices have been employed to increase the dynamism and performance of the envelope, boosting the façade composition. The adequacy of the design, functional model, and control logic would depend on the type of activity held indoors, but most importantly the type of occupants hosted.

Not all occupants perceived similarly and prefer, require, or demand the same indoor environmental conditions. Thus, depending on what the designers' choice is:

- The building could perform badly if a manual control has been envisaged without any correction or adaption (Masoso and Grobler 2010).

- An autonomous building could not provide enough satisfaction, if the performance criteria are not adjusted to the occupants' requirements, and they would feel underrated if no sense of control is given (Belafi et al. 2017; Langevin et al. 2015).

- An adaptive building could operate decently in a mixed-mode, allowing occupants' interaction and overriding the initially set activation thresholds (Gunay et al. 2014).

The type of operation affects the energy consumption of the building (i.e., environmental gains) and the frequency of activation, hence the fatigue on the materials, and the maintenance activities. Further replacement, or maintenance, interventions would enlarge the embodied energy of the system threatening its circular economy.

\section{Shading Requirement}

Taking into consideration only the lighting requirement for reading and writing activities, sufficient illuminance shall be provided under daylighting (when available) and artificial lighting. Starting from the minimum threshold established of $3001 \mathrm{x}$ and a maximum of 1000 lx (following sDA and ASE lower and upper limits established by LEED v4 (2014)) to avoid the risk of glare and modifying it according to the needs of the occupant (i.e., aged eye, protected eye, and younger eye); see Table 1.

Shading requirement has been set as the need for a lower/higher glass transmittance of the transparent portion of the building façade to regulate the daylight influx, and this would only be used when the values obtained indoors do not comply with the settings set. However, these settings were diversified to encompass a more realistic preference of different building users, and also to cover what the design regulations do not clarify: maximum illuminance values (i.e., there are only lower thresholds).

An office space $(2.95 \times 5.10 \times 3.17 \mathrm{~m})$ in Milan, Italy $\left(45^{\circ} 28^{\prime} 47^{\prime \prime} \mathrm{N} ; 9^{\circ} 13^{\prime} 47^{\prime \prime} \mathrm{E}\right)$, with $30 \%$ window-to-wall ratio (WWR) oriented toward South, was used as a case study, in which the illuminance was computed at an analysis grid at $0.8 \mathrm{~m}$ from the 
Table 1 Frequency hours of shading and lighting activation according to the lower and upper illuminance thresholds

\begin{tabular}{l|l|l|l|l|l}
\hline Condition & $E_{\min }(\mathrm{lx})$ & $E_{\max }(\mathrm{lx})$ & $\begin{array}{l}\text { Artificial } \\
\text { lighting }(\%)\end{array}$ & Shading (\%) & $\begin{array}{l}\text { Total no. } \\
\text { activation hours } \\
(\%)\end{array}$ \\
\hline Normal & 300 & 1000 & 22.86 & 49.94 & 27.20 \\
\hline $\begin{array}{l}\text { Younger } \\
\text { occupants }^{\mathrm{a}}\end{array}$ & 400 & 650 & 27.92 & 61.54 & 10.54 \\
\hline $\begin{array}{l}\text { Older } \\
\text { occupants }^{\mathrm{b}}\end{array}$ & 354 & 1180 & 25.70 & 46.08 & 28.22 \\
\hline $\begin{array}{l}\text { Glasses worn } \\
\text { occupants }^{\mathrm{a}}\end{array}$ & 265 & 600 & 21.42 & 63.36 & 15.22 \\
\hline
\end{tabular}

${ }^{a}$ Average value for a neutral condition obtained from a qualitative survey performed at Politecnico di Milano (18-22-year-old students)

${ }^{\mathrm{b}}$ Assumed value, considering the $\sim 18 \%$ decay of stimulus at the $550 \mathrm{~nm}$ wavelength of light (see Turner and Mainster 2008)

floor. The optical properties of the materials were the following: glass $\tau_{\mathrm{vis}}=0.65$; ceiling $\rho_{\text {vis }}=0.8$; internal walls $\rho_{\text {vis }}=0.5$; and floor $\rho_{\text {vis }}=0.4$.

The obtained values for different criteria were confronted against the traditional $E_{h}$ evaluation; that is, what was found from analyzing preferences of a qualitative survey applied to bachelor students and what has been suggested by Turner and Mainster (2008) due to the eyesight decay. The frequency of activation and the variances obtained due to these values have been collected and presented in Table 1, additionally in Figs. 1a and 2 annual heat maps have been included to see the behavior of illuminance and required activation during the year.

(a)

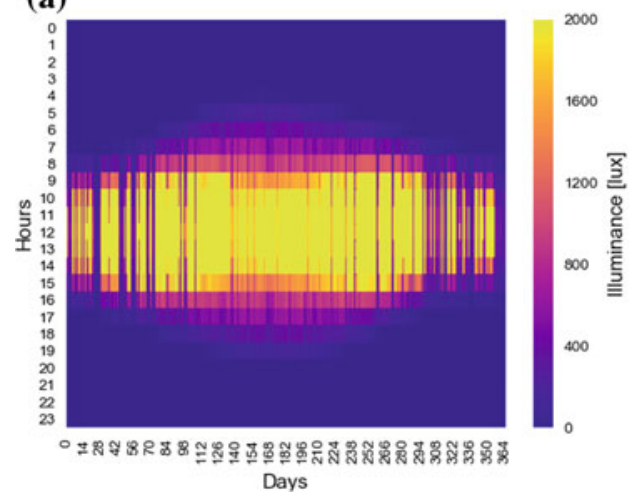

(b)

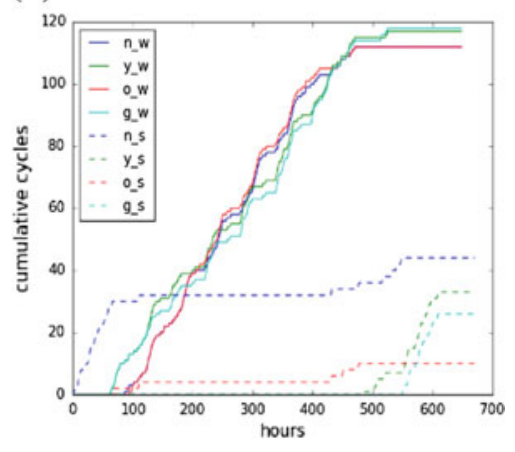

Fig. 1 Average room surface illuminance value along the year (a) and shading cycle occurrence cumulative sum throughout 3 months (i.e., summer June-Aug $(s)$ and winter Jan-Mar $(w)$ ) for normal considerations $(n)$, young $(y)$, older $(o)$, and glasses worn occupants (b) 
(a)

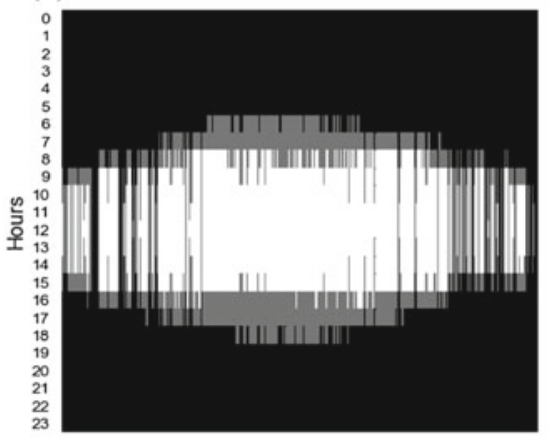

(c)

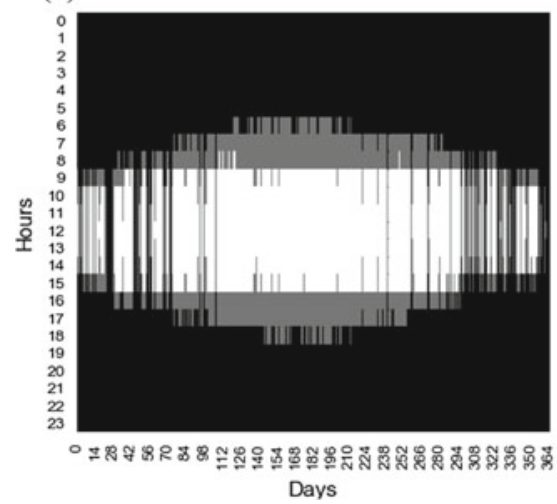

(b)

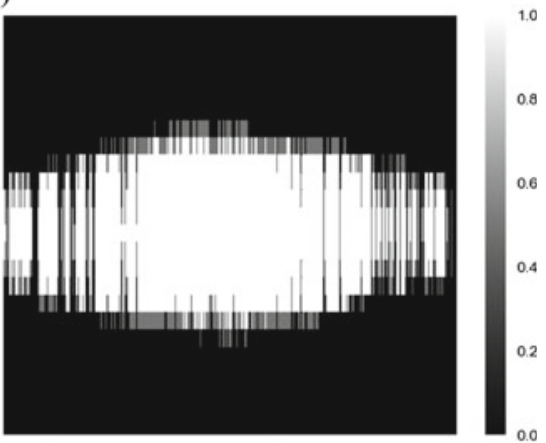

(d)

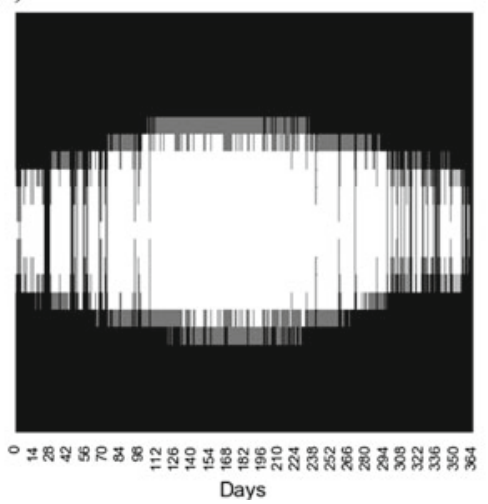

Fig. 2 Activation controls for artificial lighting (value 0), for shading (value 1) and no activation required (value 0.5). For a normal consideration, $\mathbf{b}$ younger occupants, $\mathbf{c}$ older occupants, and d glass worn occupants

\subsection{Frequency of Use}

The frequency of use of both shading and lighting appliances has been estimated from an annual simulation using the validated ray-tracing software radiance presented by Ward and Shakespeare (1998). It has been assumed that the values reported in Table 1 are a hypothetical ideal case in which the shadings are correctly operated by the building, and in which they have been adapted to a more realistic hosted occupancy type. 


\section{Conclusions}

The need for clarifying the type of occupancy indoors is clear, as the variance of the activation hours of the electrical appliances and/or shading can reach a difference of $\sim 13 \%$ generating a much larger quantity of cycles that could reduce the life expectancy of the building systems. Moreover, the hours of comfort have a well significant difference when considering one range or the other, for instance, for occupants wearing glasses the number of hours in which no intervention was required was $\sim 15 \%$; meanwhile for the established benchmark (i.e., between 300 and 1000 lx), it was $\sim 27 \%$. In terms of cycles, it is clear how the number of activations varies from one occupancy type to the other, given what is shown in Fig. 1b. For summer, the amount of cycles is reduced as they are mainly $\mathrm{ON}$; meanwhile for the winter, a higher variance is noted due to lower daylighting availability and the perpendicularity of the light influx.

Further studies are foreseen to establish a more reliable visual comfort range for the horizontal illuminance that would allow to improve the building design. Additional surveys on diverse occupant samples are expected to assess different influential physical features.

\section{Standards and Laws}

American Society of Heating, R. and A. C. E. (ASHRAE). (2013). ASHRAE Standard 55-2013 Thermal Environmental Conditions for Human Occupancy. Ashrae, 2004.

Council, US Green Building. LEED v4 for building design and construction. USGBC Inc. (2014).

\section{References}

Belafi, Z., Hong, T., \& Reith, A. (2017). Smart building management versus intuitive human control-Lessons learnt from an office building in Hungary. Building Simulation, 10(6), 811-828.

Gunay, H. B., O'Brien, W., Beausoleil-Morrison, I., \& Huchuk, B. (2014). On adaptive occupantlearning window blind and lighting controls. Building Research and Information, 42(6), 739-756.

Langevin, J., Gurian, P. L., \& Wen, J. (2015). Tracking the human-building interaction: A longitudinal field study of occupant behavior in air-conditioned offices. Journal of Environmental Psychology, 42, 94-115.

Masoso, O. T., \& Grobler, L. J. (2010). The dark side of occupants' behaviour on building energy use. Energy and Buildings, 42(2), 173-177.

Turner, P. L., \& Mainster, M. A. (2008). Circadian photoreception: Ageing and the eye's important role in systemic health. British Journal of Ophthalmology, 92(11), 1439-1444.

Ward, G., \& Shakespeare, R. (1998). Rendering with radiance: The art and science of lighting visualization. Morgan Kaufman. 
Open Access This chapter is licensed under the terms of the Creative Commons Attribution 4.0 International License (http://creativecommons.org/licenses/by/4.0/), which permits use, sharing, adaptation, distribution and reproduction in any medium or format, as long as you give appropriate credit to the original author(s) and the source, provide a link to the Creative Commons license and indicate if changes were made.

The images or other third party material in this chapter are included in the chapter's Creative Commons license, unless indicated otherwise in a credit line to the material. If material is not included in the chapter's Creative Commons license and your intended use is not permitted by statutory regulation or exceeds the permitted use, you will need to obtain permission directly from the copyright holder.

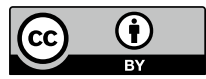

